\title{
Chemical Composition and Inhibitory Effect of the Essential Oil from Mentha Spicata Irrigated by Wastewater on the Alkaline Corrosion of Aluminum
}

\author{
F. Bensabah ${ }^{1^{*}}$, S. Houbairi ${ }^{1}$, M. Essahli ${ }^{1}$, A. Lamiri ${ }^{1}$ and J. Naja ${ }^{1}$
}

1 : University Hassan 1, Faculty of Science and Techniques, Laboratory of Applied Chemistry and Environment, B.P. 577, Settat, Morocco

\section{ABSTRACT} bensabah_fati@yahoo.fr

Mentha Spicata irrigated by wastewater from the city of Settat (Morocco) was tested as corrosion inhibitor of aluminum in $0.1 \mathrm{M} \mathrm{Na}_{2} \mathrm{CO}_{3}$ using polarization method and weight loss measurements. The inhibition efficiency of mentha spicata oil was calculated and compared. We note good agreement between these methods. The results obtained showed that the tested inhibitor reduces the kinetic process of corrosion of aluminum. Its efficiency increases with the concentration and attained $82 \%$ at $1600 \mathrm{ppm}$. The effect of temperature on the corrosion behaviour of aluminum in $0.1 \mathrm{M} \mathrm{Na}_{2} \mathrm{CO}_{3}$ was also studied in the range $283 \mathrm{~K}$ and $313 \mathrm{~K}$. The thermodynamic data of activation were determined. The analysis of mentha spicata oil obtained by hydro-distillation using gas chromatography (GC) showed that the major components are carvone $57.11 \%$ and limonene $27.77 \%$.

\section{Indexing terms/Keywords}

Corrosion inhibition; aluminum; Mentha Spicata; essential oil; wastewater.

\section{Council for Innovative Research}

Peer Review Research Publishing System

\section{Journal: Journal of Advances in Chemistry}

Vol. 7, No. 3

\section{editor@cirworld.com}




\section{INTRODUCTION}

One of the most important applications of aluminum and its alloys is found in aluminum -air technology [1] Aluminum alloys are widely used in structures where a high strength to weight ratio is important, such as in the transportation industry. Aluminum has a natural corrosion protection from its oxide layer, but if exposed to aggressive environments it may corrode. Still, if correctly fabricated, constructions of aluminum may be reliable and have long service life, the known hazard effects of most synthetic corrosion inhibitors are the motivation for the use of some natural products.

Recently, Naturally occurring substances of both plant and animal origin which are readily available, cheap, renewable, eco-friendly and eco-logically acceptable, have been successfully used as a replacement for the organic and inorganic inhibitors [2-5].Plant extracts have again become important as an environmentally acceptable, readily available and renewable source for a wide range of needed inhibitors. Plant extracts are viewed as an incredibly rich source of naturally synthesized chemical compounds that can be extracted by simple procedures with low cost. However, synergistic (and antagonistic) effects are often expected with these mixtures of inhibitors that may affect their inhibition efficiency. Several investigations have been reported using such economic plant extracts [6-16]. They showed that the solution extract of the leaves serves as an excellent inhibitors. The existing data show that most organic inhibitors act by adsorption at the metal/solution interface. This phenomenon could take place via (i) electrostatic attraction between the charged metal and the charged inhibitor molecules, (ii) dipole-type interaction between unshared electron pairs in the inhibitor with the metal, (iii) p electrons-interaction with the metal, and (iv) a combination of all of the above [17]. The adsorption process depends on the electronic characteristics of the inhibitor, the nature of the surface, the temperature and pressure of the reaction, steric effect, multilayer adsorption and a varying degree of surface site activity.

Also we found the Mentha Spicata irrigated by wastewater has been good corrosion inhibitor of Aluminum in acidic solution $1 \mathrm{M} \mathrm{HCl}$ [18]. However, to the best of our knowledge, lippia citriodora irrigated by wastewater has not been used as a corrosion inhibitor for aluminum.

The aim of the present work is to test extracts of Mentha oil as inhibitors for the alkaline corrosion of aluminum and to discuss their inhibition mechanism.

\section{Experimental part}

\section{2-1 Plant material}

The planting was made in May 2009 in experimental plots located in the Faculty of Sciences and Technics of SettatMorocco (FSTS). Irrigation was done with the urban wastewater purified by lagoons from the city of Settat-Morocco. The harvests have been handmade and the plants were cut $15-30 \mathrm{~cm}$ above the ground. The quality of essential oils was also determined using fresh leaves of spearmint.

\section{2-2 Water quality irrigation}

The physico-chemical parameters (temperature, $\mathrm{pH}$ and conductivity) were measured on site by means of a mercury thermometer $\left(1 / 10^{\circ} \mathrm{C}\right)$, a portable $\mathrm{pH}$ meter Lutron $(\mathrm{pH}-206)$ and conductivity meter HANNA (HI-8733 with a margin of error of $2 \%$ ). In the laboratory, the waters were analyzed for major ions $\left(\mathrm{Ca}^{2+}, \mathrm{Mg}^{2+}, \mathrm{NH}_{4}^{+}, \mathrm{Cl}^{-}, \mathrm{SO}_{4}^{-}\right.$and $\left.\mathrm{HCO}_{3}^{-}\right)$and the nutritive salts. Chlorides and alkalinity were determined by titration (Appendix Table; Rodier 1996). The analysis of metallic trace elements was carried out by the ICP technique.

\section{2-3 Extraction of mentha essential oil}

The distillation apparatus consisted of a heating cap, a $1.5 \mathrm{~L}$ extraction flask, a cooling system and a receiver for hydrodistillate. Thirty grams of fresh plant leaves and $800 \mathrm{~mL}$ of water were used and the distillation was carried out for 3 hours after the mixture reached boiling at $100^{\circ} \mathrm{C}$. Hydrodistillation repetitions were done at least in duplicate depending on the availability of the spearmint leaves. The essential oil obtained was dried under anhydrous sodium sulfate and stored at $4{ }^{\circ} \mathrm{C}$ in the dark before analysis. And the yield of oil derived from the dried leaves was $0.58 \%$.

\section{2-4 Gas chromatography-mass spectrometry}

The essential oil was characterized using a gas chromatograph Trace GC Ultra equipped with an auto injector (Triplus) directly interfaced with a mass spectrophotometer with a flame ionization detector (Pdains Q). Capillary column was DB-5 ( $5 \%$ of diphenyl and $95 \%$ of dimethylpolysiloxane), $30 \mathrm{~m}$ in length, and $0.25 \mathrm{~mm}$ thickness. Separation conditions were: 25 ${ }^{\circ} \mathrm{C}$ for $2 \mathrm{~min}, 25-200^{\circ} \mathrm{C}$ at $4{ }^{\circ} \mathrm{C} / \mathrm{min}$, and $180-300^{\circ} \mathrm{C}$ at $40{ }^{\circ} \mathrm{C} / \mathrm{min}$. Temperature of the injector was $220{ }^{\circ} \mathrm{C}$. The volume injected was $0.1 \mu \mathrm{L}$. The carrier gas was helium with a flow rate of $1.4 \mathrm{~mL}$. $\mathrm{min}^{-1}$. The oil constituents were identified by comparison of their retention indices and their mass spectra with those of authentic samples. Quantitative analysis (in percent) was performed by peak area measurement.

\section{2-5 Weight loss tests}

Distilled water and $\mathrm{Na}_{2} \mathrm{CO}_{3}$ were used for preparing aggressive solutions. Prior to all measurements, the aluminum samples were polished with different emery papers up to 1200 grade, washed thoroughly with distilled water, degreased with acetone and drying at room temperature. The solution volume was $30 \mathrm{~mL}$. The used aluminum specimens had a rectangular form, with a surface area of $9 \mathrm{~cm}^{2}$. The immersion time for the weight loss was $1 \mathrm{~h}$ at $25^{\circ} \mathrm{C}$. After the corrosion test, the specimen of aluminum was carefully washed in distilled water, dried and then weighed. 
The rinse removed loose segments of the film of the corroded samples. Duplicate experiments were performed in each case and the mean value of the weight loss was reported. Weight loss allowed us to calculate the mean corrosion rate as expressed in $\mathrm{mg} \cdot \mathrm{cm}^{-2} \cdot \mathrm{h}^{-1}$.

\section{2-6 Rp, polarisation and EIS measurements}

Electrochemical measurements were carried out in a conventional three-electrode electrolysis cylindrical Pyrex glass cell. The working electrode (WE) in the form of disc cut from aluminum has a geometric area of $1 \mathrm{~cm}^{2}$. A saturated calomel electrode (SCE) and a disc platinum electrode were used respectively as reference and auxiliary electrodes. The temperature was thermostatically controlled at $25^{\circ} \mathrm{C}$. The WE was abraded with different emery papers up to 1200 grade, degreased with acetone, and rinsed with distilled water before use.

Running on a compatible computer, the Voltab Master4 Software communicates with Instruments potentiostat-galvanostat model PGZ100 at a scan rate of $20 \mathrm{mV} / \mathrm{sec}$. Before recording the polarization curves, the working electrode is maintained for $10 \mathrm{~min}$ to Ecorr. The resulting current is plotted as a function of the potential. Polarization resistance $(\mathrm{Rp})$ values were obtained from the current potential plot. The scan rate was $10 \mathrm{mV} / \mathrm{sec}$. The electrochemical impedance spectroscopy (EIS) measurements were carried out with an electrochemical system which included a digital potentiostat model Volta lab PGZ 100 computer at Ecorr after immersion in solution, the circular surface of aluminum exposing of $1 \mathrm{~cm}^{2}$ to the solution was used as working electrode.

Frequencies between $100 \mathrm{kHz}$ and $10 \mathrm{mHz}$ were superimposed on the corrosion potential. The impedance diagrams are given in the Nyquist representation. Values of Rt and Cdl were obtained from Nyquist plots.

\section{Results and discussion}

\section{3-1 Physicochemical analysis of irrigation water}

Throughout the experiment, the chemical composition of this water source of irrigation has been determined and is detailed in Table 1. The gravity irrigation planting is done 1 day / 3 sources, and water was analyzed at each irrigation. Wastewater physico-chemical analyzes showed that the chemical oxygen demand (COD) is high and the concentration of $\mathrm{Cl}^{-}$ion exceeds the standard because urban water is responsible by chloride ions. Other physico-chemical parameters meet the standards as metallic trace elements.

Table 1. Characterization of wastewater purified by lagoons used for irrigation in the study.

\begin{tabular}{|c|c|c|}
\hline \multirow{2}{*}{ Parameter } & \multicolumn{2}{|c|}{ Wastewater purified } \\
\hline & Average value & Norm(") \\
\hline $\mathrm{pH}$ & 7,63 & $6,5-8,4$ \\
\hline Temperature $/{ }^{\circ} \mathrm{C}$ & 29,36 & 35 \\
\hline Conductivity at $20^{\circ} \mathrm{C} \mu \mathrm{s} / \mathrm{cm}$ & 1313,64 & 1200 \\
\hline Biological Oxygen Demand $\mathrm{mgO}_{2} / \mathrm{L}$ & 27 & - \\
\hline Chemical Oxygen Demand $\mathrm{mgO}_{2} / \mathrm{L}$ & 656,36 & - \\
\hline $\mathrm{NH}_{4}^{+} \mathrm{mg} / \mathrm{L}$ & 11,25 & - \\
\hline $\mathrm{Cl}^{-} \mathrm{mg} / \mathrm{L}$ & 850,7 & 350 \\
\hline $\mathrm{Ca}^{2+} \mathrm{mg} / \mathrm{L}$ & 97,94 & - \\
\hline $\mathrm{Mg}^{2+} \mathrm{mg} / \mathrm{L}$ & 53,63 & - \\
\hline $\mathrm{HCO}_{3}^{-} \mathrm{mg} / \mathrm{L}$ & 67,65 & 512 \\
\hline $\mathrm{N}-\mathrm{NO}_{2}^{-} \mathrm{mg} / \mathrm{L}$ & 0,09 & 30 \\
\hline $\mathrm{PO}_{4}{ }^{3-} \mathrm{mg} / \mathrm{L}$ & 3,27 & - \\
\hline $\mathrm{SO}_{4}{ }^{2-} \mathrm{mg} / \mathrm{L}$ & 124,00 & 350 \\
\hline Suspended matter $\mathrm{mg} / \mathrm{L}$ & 130,4 & 200 \\
\hline $\mathrm{Cd} \mathrm{mg} / \mathrm{L}$ & $\leq 0.002$ & 0,01 \\
\hline $\mathrm{Cr} \mathrm{mg} / \mathrm{L}$ & 0.004 & 1 \\
\hline Cu mg/L & 0,0075 & 0,2 \\
\hline $\mathrm{Ni} \mathrm{mg/L}$ & 0,012 & 2 \\
\hline Zn mg/L & 0,089 & 2 \\
\hline $\mathrm{Hg} \mathrm{mg/L}$ & $\leq 0.01$ & 0,001 \\
\hline
\end{tabular}


$\left(^{\star}\right)$ : Standards of water quality for irrigation S.E.E.E-2007- Morocco (Secretariat of the Ministry of Energy, Mines, Water and Environment).

\section{3-2 Chemical composition of mentha spicata essential oil}

The GC-MS analyzes of mentha spicata essential oil irrigated by urban wastewater purified by lagoons from the city of Settat-Morocco are presented in the Table 2.

Table 2. Chemical composition of Mentha spicata essential oil irrigated by wastewater from the city of SettatMorocco) purified by lagoon

\begin{tabular}{|l|c|}
\hline \multicolumn{1}{|c|}{ Compounds } & A \% \\
\hline $\boldsymbol{\alpha}$-Pinene & 0,69 \\
\hline Camphene & Trace \\
\hline 3-Carene & 1,01 \\
\hline $\boldsymbol{\beta}$-Phellandrene & 0,60 \\
\hline Limonene & 27,77 \\
\hline 1,8-Cineole & 0,28 \\
\hline cis-Ocimene & Trace \\
\hline Borneol & 0,84 \\
\hline sabinene hydrate & 0,39 \\
\hline Isocyclocitral & 1,71 \\
\hline trans-carveol & 1,79 \\
\hline Pulegone & 0,30 \\
\hline Carvone & 57,11 \\
\hline bornyl acetate & 0,27 \\
\hline iso-limonene & Trace \\
\hline $\boldsymbol{\beta}$-bourbonene & 0,71 \\
\hline Caryophyllene & Absent \\
\hline Aromandrene & 0,50 \\
\hline germacrene D & 0,65 \\
\hline Calamenene & 0,22 \\
\hline
\end{tabular}

A: plots irrigated by wastewater from the city of Settat treated lagoon.

Mentha spicata of Morocco still contains majority composed: carvone, limonene and trans-carveol. In general, the spearmint oil composition in this study was similar to that in other reports [19, 20, and 21].

\section{3-3 Weight loss tests}

The corrosion rate (Wcorr) of aluminum in $0.1 \mathrm{M} \mathrm{Na}_{2} \mathrm{CO}_{3}$ solution at various contents of the natural oil tested was determined after $1 \mathrm{~h}$ of immersion period at $25^{\circ} \mathrm{C}$. Values of corrosion rates and inhibition efficiencies are given in Table 3. In the case of the weight loss method, the inhibition efficiency (Ew \%) was determined by the following relation:

$$
\text { Ew } \%=\frac{W_{\text {corr }}-W_{\text {corr }(i n h)}}{W_{\text {corr }}} \times 100
$$

Where Wcorr and Wcorr(inh) are the corrosion rates of aluminum in the absence and presence of the oil, respectively. The analysis of these results (Table 3 and Fig. 1) shows clearly that the corrosion rate decreases $\left(\mathrm{W}\left(\mathrm{mg} / \mathrm{h} . \mathrm{cm}^{2}\right)\right.$ while the inhibition efficiency (Ew (\%)) increases with increasing inhibitor concentration, reaching a maximum value of $79 \%$ at a concentration of $1600 \mathrm{ppm}$. This behaviour can be attributed to the increase of the surface covered $\ominus($ Ew \%/100) and this is due to the adsorption of natural compounds on the surface of the metal as the inhibitor concentration increases. We can conclude that mentha oil is a good corrosion inhibitor for aluminum in $0.1 \mathrm{M} \mathrm{Na}_{2} \mathrm{CO}_{3}$ solution. 
Table 3. Gravimetric results of aluminum in $0.1 \mathrm{M} \mathrm{Na}_{2} \mathrm{CO}_{3}$ without and with addition of the natural oil at various contents $\left(t=1 \mathrm{~h} . T=25^{\circ} \mathrm{C}\right)$.

\begin{tabular}{|c|c|c|}
\hline Concentration /ppm & $\mathrm{W} \mathrm{mg} / \mathrm{cm}^{2} \cdot \mathrm{h}$ & Ew $/ \%$ \\
\hline Blank & 0.347 & --- \\
\hline 1000 & 0.187 & 46.11 \\
\hline 1200 & 0.152 & 56.19 \\
\hline 1400 & 0.114 & 67.15 \\
\hline 1600 & 0.072 & 79.25 \\
\hline 1800 & 0.070 & 79.83 \\
\hline 2000 & 0.070 & 79.83 \\
\hline
\end{tabular}

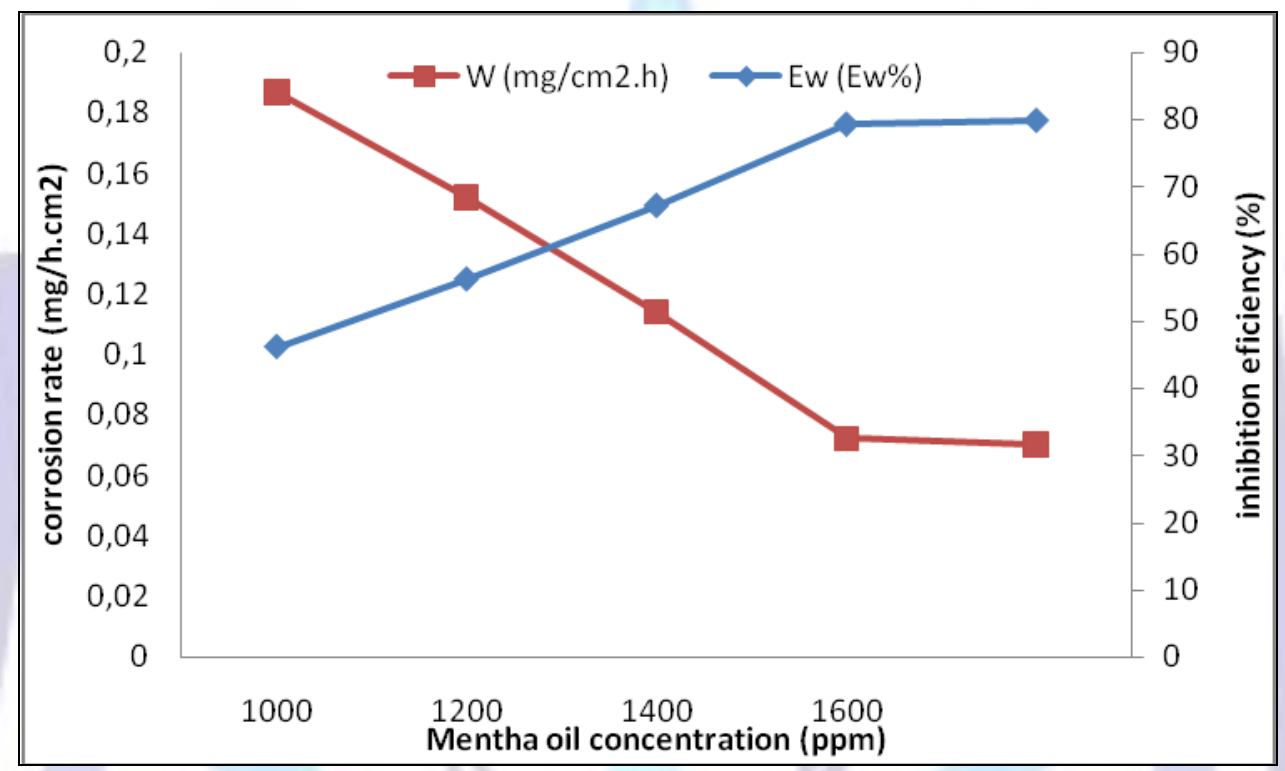

Figure 1. Variation of corrosion rate and inhibition efficiency of aluminum in $0.1 \mathrm{M} \mathrm{Na} \mathrm{CO}_{3}$ without and with mentha spicata oil.

\section{3-4 Polarisation measurements}

Current-potential characteristics resulting from cathodic and anodic polarisation curves of aluminum in 0.1 molar sodium carbonate at various concentrations of the tested mentha oil are evaluated (Fig. 2).

Table 4 collects the corrosion kinetic parameters such as Ecorr, Icorr, $\beta c$, and $\beta a$ obtained from potentiodynamic polarization curves for aluminum in $0.1 \mathrm{M} \mathrm{Na}_{2} \mathrm{CO}_{3}$ containing different concentrations of mentha oil. In the case of polarization method the relation determines the inhibition efficiency (EI \%):

$$
\mathrm{El} \%=\frac{I_{\text {corr }}-I_{\text {corr }(i n h)}}{I_{\text {corr }}} \times 100
$$

Where Icorr and Icorr(inh) are the corrosion current density values without and with the inhibitor, respectively. 


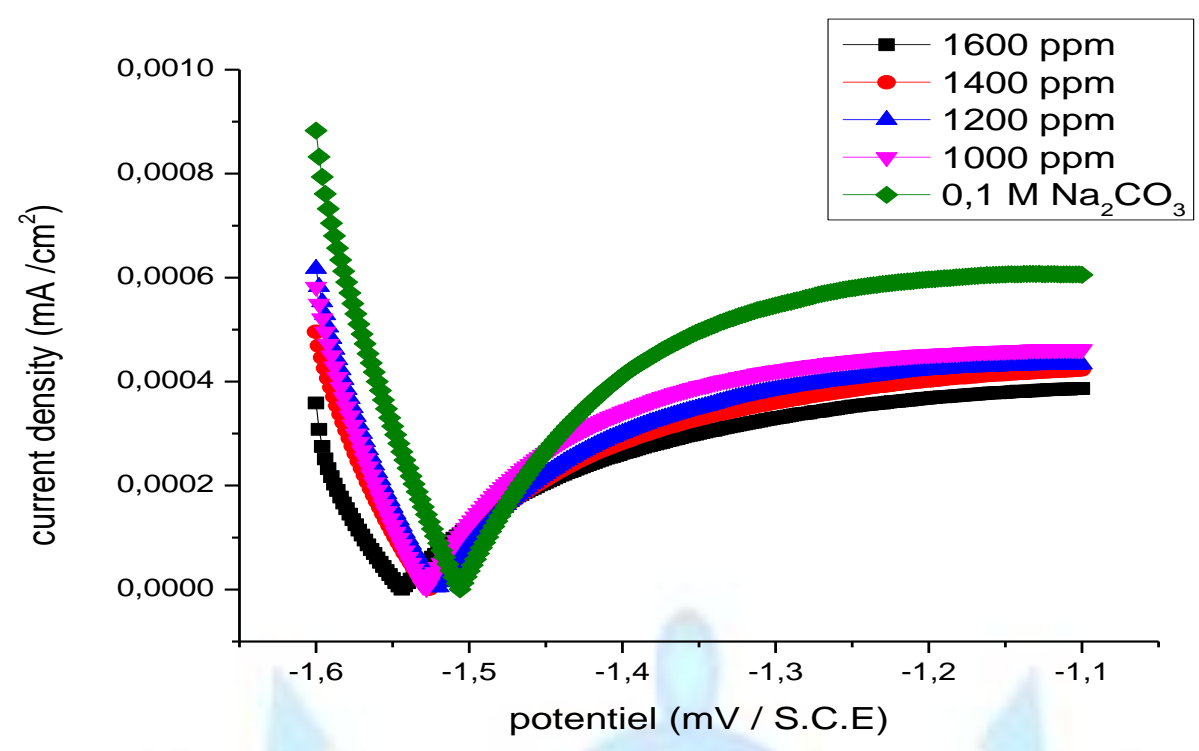

Figure 2. Potentiodynamic polarization curves for aluminum in $0.1 \mathrm{M}$ sodium carbonate in absence and presence of different Mentha oil concentrations.

Figure 2 represent the anodic and cathodic polarization curves for aluminum in $0.1 \mathrm{M}$ sodium carbonate in absence and presence of different concentration of mentha oil. As seen, from this figure the mentha oil inhibit both cathodic and anodic parts of the polarization curves.

Table 4 shows the electrochemical polarization parameters, where the corrosion current density, (Icorr), was calculated from the intersection of anodic and cathodic Tafel lines; corrosion potential (Ecorr); Corrosion current density and anodic and cathodic Tafel line slopes $(\mathrm{Ba}$, and $\mathrm{\beta c}$ ) for different concentrations of mentha oil. The data revealed that, for all concentrations under study, the corrosion current density that is directly proportional to corrosion rate decreases with increasing the mentha oil concentration.

The values of Ecorr shifted slightly to less positive potentials with increasing the concentration of mentha oil. The values of the anodic Tafel line slope $(\mathrm{Ba})$ in presence of the extracts show higher values probably due to the effect of diffusion process.

The tabulated data also indicate that mentha oil inhibits the alkaline corrosion of aluminum efficiently and \%P reaches about $82.02 \%$ for the solutions containing 1600 ppm of the oil.

Table 4. Electrochemical parameters of aluminum at various concentrations of Mentha oil studied in $1 \mathrm{M} \mathrm{HCl}$ at $25^{\circ} \mathrm{C}$. Corresponding corrosion inhibition efficiencies.

\begin{tabular}{|c|c|c|c|c|c|c|}
\hline Inhibitor & $\begin{array}{c}\text { Concentration } \\
\mathbf{p p m}\end{array}$ & $\begin{array}{c}\mathbf{E}_{\text {corr }} \\
\mathbf{m V} / \mathbf{S C E}\end{array}$ & $\begin{array}{c}\text { Icorr } \\
\mu \mathrm{A} / \mathbf{C m}^{2}\end{array}$ & $\begin{array}{c}\boldsymbol{\beta} \mathbf{c} \\
\mathbf{m V}\end{array}$ & $\begin{array}{c}\boldsymbol{\beta} \mathbf{a} \\
\mathbf{m V}\end{array}$ & $\mathbf{E}_{\mathbf{I}} \%$ \\
\hline \multirow{3}{*}{ Blank } & ---- & -1509.3 & 150.128 & -124.1 & 219.9 & -- \\
\hline \multirow{3}{*}{ Mentha oil } & 1000 & -1540.1 & 81.075 & -71.7 & 112.1 & 45.99 \\
\cline { 2 - 7 } & 1200 & -1531.4 & 75.046 & -84.4 & 145.1 & 50.01 \\
\cline { 2 - 7 } & 1400 & -1529.6 & 46.539 & -86.3 & 149.1 & 69.00 \\
\cline { 2 - 7 } & 1600 & -1547.2 & 27.023 & -98.6 & 303.8 & 82.00 \\
\hline
\end{tabular}

\section{3-5 Electrochemical impedance spectroscopy (EIS)}

The corrosion behaviour of aluminum in 0.1 molar sodium carbonate, in the absence and presence of mentha oil, is also investigated by electrochemical impedance spectroscopy (EIS) at $25^{\circ} \mathrm{C}$. The charge-transfer resistance (Rt) values are calculated from the difference in impedance at lower and higher frequencies, as suggested by Tsuru et al. [22]. The double layer capacitance $\left(\mathrm{C}_{\mathrm{dl}}\right)$ and the frequency at which the imaginary component of the impedance is maximal (-Zmax) are found as represented in equation: 


$$
\mathrm{C}_{\mathrm{dl}}=\frac{1}{R . T}, \text { where } \mathrm{w}=2 \pi \mathrm{f}_{\max }
$$

Impedance diagrams are obtained for frequency range $100 \mathrm{KHz}-10 \mathrm{mHz}$ for aluminum in 0.1 molar sodium carbonate in the presence and absence of mentha oil. Nyquist plots for aluminum in $1 \mathrm{M} \mathrm{HCl}$ and in $1800 \mathrm{ppm}$ concentration of mentha oil are presented in Fig 3.

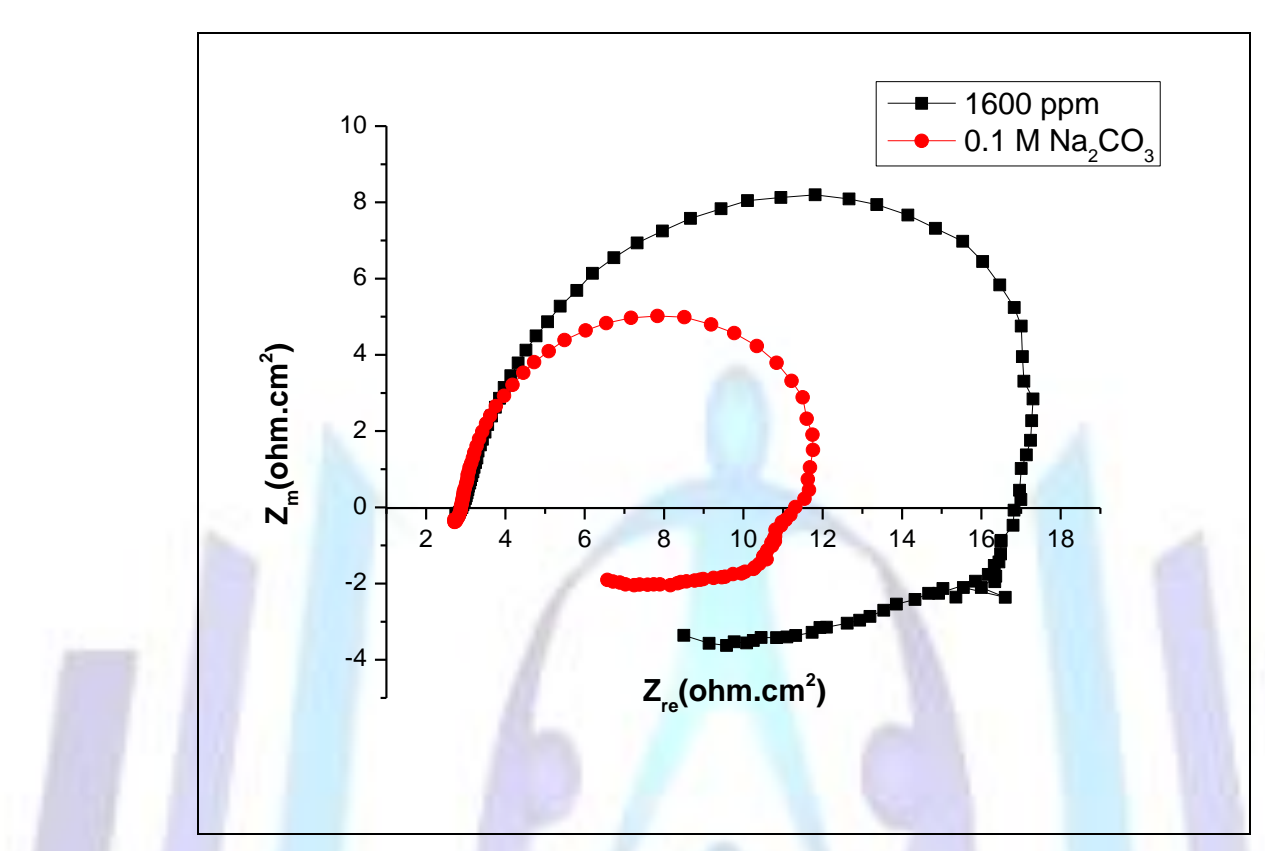

Figure 3. Nyquist plots of aluminum with and without mentha oil.

The Nyquist impedance plots explain that the impedance response consists of capacitive semicircle followed by inductive loop indicating that the dissolution process occurs under activation control. The inductive loop is generally attributed to the adsorption of the species resulting from metal dissolution and hydrogen adsorption [23]. The impedance spectra for different Nyquist plots were analyzed by fitting the experimental data to a simple equivalent circuit model (figure 4) which includes the solution resistance $R s$ and the double layer capacitance $\left(\mathrm{C}_{\mathrm{dl}}\right)$ which is placed in parallel to charge transfer resistance element, Rt. The Rt value is a measure of electron transfer across the surface and is inversely proportional to corrosion rate.
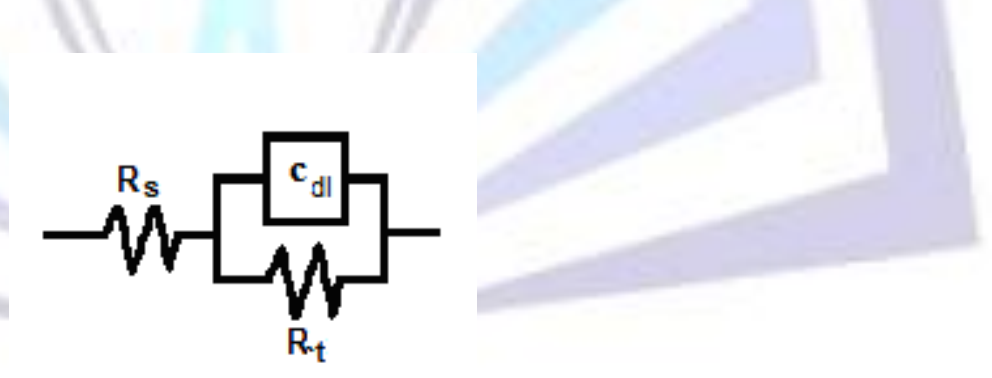

Figure 4. The equivalent circuit model.

Table 5 presents values of charge transfer resistance, Rt double-layer capacitance, $C_{d l}$, and $f_{\max }$ derived from Nyquist plots and inhibition efficiency; the inhibition efficiency gotten from the charge-transfer resistance is calculated by the following relation:

$$
\text { ERt } \%=\frac{R_{t}^{I}-R_{t}}{R_{t}^{I}} \times 100
$$

Rt and R't are the charge-transfer resistance values without and with inhibitor, respectively. Rt is the diameter of the loop. 
Table 5. Characteristic parameters evaluated from the impedance diagram for aluminum without and with of mentha oil.

\begin{tabular}{|c|c|c|c|c|}
\hline Inhibitor & $\mathbf{R t}$ ohm.cm & $\mathbf{f}_{\max } / \mathbf{H z}$ & $\begin{array}{c}\mathbf{C}_{\mathrm{dl}} \\
\boldsymbol{\mu F / \mathbf { c m } ^ { 2 }}\end{array}$ & $\mathbf{E}_{\mathrm{Rt}} \%$ \\
\hline $\mathrm{Na}_{2} \mathrm{CO}_{3} \mathbf{0 . 1 M}$ & 58.5 & 102.27 & 26.6 & ------ \\
\hline $\begin{array}{c}\text { Mentha oil } \\
\mathbf{1 6 0 0} \mathbf{~ p p m}\end{array}$ & 321.6 & 21.89 & 22.6 & 81.80 \\
\hline
\end{tabular}

Increasing Rt values with the concentration of the oil, suggesting decrease of the corrosion rate since the Rt value, is a measure of electron transfer across the surface, and inversely proportional to the corrosion rate. The decrease in the $\mathrm{C}_{\mathrm{dl}}$ values could be attributed to the adsorption of the chemical constituents of the extracts at the metal surface [24].

The tabulated data also indicate that mentha oil has considerable effect for the corrosion of aluminum in $0.1 \mathrm{M} \mathrm{Na}_{2} \mathrm{CO}_{3}$ solution.

As seen, the inhibition efficiency of the mentha oil is arranged according to table 6 . The data show that: there is a considerable agreement between the data obtained from the three techniques, Weight loss, polarization, and EIS.

Table 6. comparison between $\% \mathrm{P}$ of mentha oil $(1600 \mathrm{ppm})$ which obtained from weight loss, polarization and impedance technique.

\begin{tabular}{|c|c|c|c|}
\hline & weight loss & polarization & impedance technique \\
\hline Mentha oil & 79.83 & 82.02 & 81.80 \\
\hline
\end{tabular}

\section{Mechanism of corrosion of aluminum in alkaline solutions}

a) The anodic reaction (dissolution of aluminum):

The anodic potintiodynamic polarization curves of aluminum in $0.1 \mathrm{M} \mathrm{Na}_{2} \mathrm{CO}_{3}$ in absence or in presence of the mentha oil show a limiting current indicating that the dissolution of aluminum is controlled by the diffusion of $\mathrm{Al}(\mathrm{OH})_{4}^{-}$or $\mathrm{AlO}_{2}^{-}$from the surface of the metal to the bulk of solution. Then the anodic dissolution of aluminum can be represented as:

Or

$$
\begin{aligned}
\mathrm{Al}+4 \mathrm{OH}^{-} & \rightleftharpoons \mathrm{Al}(\mathrm{OH})_{4}^{-}+3 \mathrm{e}^{-} \\
\mathrm{Al}+4 \mathrm{OH}^{-} & \rightleftharpoons \mathrm{AlO}_{2}^{-}+2 \mathrm{H}_{2} \mathrm{O}+3 \mathrm{e}^{-}
\end{aligned}
$$

b) The cathodic reaction (reduction of water):

The cathodic polarization curve of aluminum in $0.1 \mathrm{M} \mathrm{Na}_{2} \mathrm{CO}_{3}$ in absence or in presence of the mentha oil show Tafel behaviour indicating that the reduction process is controlled by charge transfer and can be presented by:

$$
\mathrm{H}_{2} \mathrm{O}+\mathrm{e}^{-} \underset{1 / 2}{\rightleftharpoons} \mathrm{H}_{2}+\mathrm{OH}^{-}
$$

c) The overall corrosion reaction:

The impedance spectroscopy data of aluminum $0.1 \mathrm{M} \mathrm{Na}_{2} \mathrm{CO}_{3}$ in absence or in presence of the mentha oil measured at the equilibrium potential indicated that the corrosion of aluminum is controlled by charge transfer. This means that the reduction of water at cathodic areas is the slow step of corrosion of aluminum. The equation corresponding to the overall reaction of corrosion of aluminum in $0.1 \mathrm{M} \mathrm{Na} \mathrm{CO}_{3}$ solution can be obtained if equation (7) is multiplied by 3 and then added to equation (9):

$$
\begin{gathered}
3 \mathrm{H}_{2} \mathrm{O}+3 \mathrm{e}^{-} \rightarrow 3 / 2 \mathrm{H}_{2}+3 \mathrm{OH}^{-} \\
\mathrm{Al}+4 \mathrm{OH}^{-} \rightleftharpoons \mathrm{AlO}_{2}^{-}+2 \mathrm{H}_{2} \mathrm{O}+3 \mathrm{e}^{-} \\
\mathrm{Al}+\mathrm{H}_{2} \mathrm{O}+\mathrm{OH}^{-} \rightleftharpoons 3 / 2 \mathrm{H}_{2}+\mathrm{AlO}_{2}^{-}
\end{gathered}
$$




\section{3-6 Effect of temperature}

The effect of temperature on the corrosion behaviour of aluminum in $0.1 \mathrm{M} \mathrm{Na}_{2} \mathrm{CO}_{3}$ containing inhibitor at a concentration $1600 \mathrm{ppm}$ is studied in the temperature range $10-40^{\circ} \mathrm{C}$ using weight loss measurements. Table 7 regroups the corresponding obtained results.

Table 7. Effect of temperature on the aluminum corrosion in the presence and absence of 1600 ppm oil for 1 hour.

\begin{tabular}{|c|c|c|c|}
\hline Temperature $/{ }^{\circ} \mathbf{C}$ & $\mathbf{W ~} \mathbf{~ m g} / \mathbf{c m}^{2} . \mathbf{h}$ & W' $\mathbf{~ m} / \mathbf{c m}^{2} \cdot \mathbf{h}$ & $\mathbf{E} \%$ \\
\hline $\mathbf{1 0}$ & 0.231 & 0,032 & 86.15 \\
\hline $\mathbf{2 0}$ & 0.304 & 0,055 & 81.91 \\
\hline $\mathbf{3 0}$ & 1.267 & 0.393 & 68.98 \\
\hline $\mathbf{4 0}$ & 1.937 & 0.736 & 62.00 \\
\hline
\end{tabular}

It is obvious that the corrosion rate increases both in the uninhibited and inhibited alkaline solution with the rise of temperature. The presence of inhibitor leads to the decrease of the corrosion rate, E\%, which decreases with the increase of temperature.

The following relation can determine the apparent activation energy:

$$
\text { Wcorr }=k \exp \left(-E_{a} / R T\right) \text { and } W^{\prime} \text { corr }=k^{\prime} \exp \left(-E_{a}^{\prime} / R T\right)
$$

W'corr and Wcorr are the corrosion rates of aluminum with and without inhibitor, respectively. E'a and Ea are the apparent activation energies in the presence and absence of inhibitor, respectively.

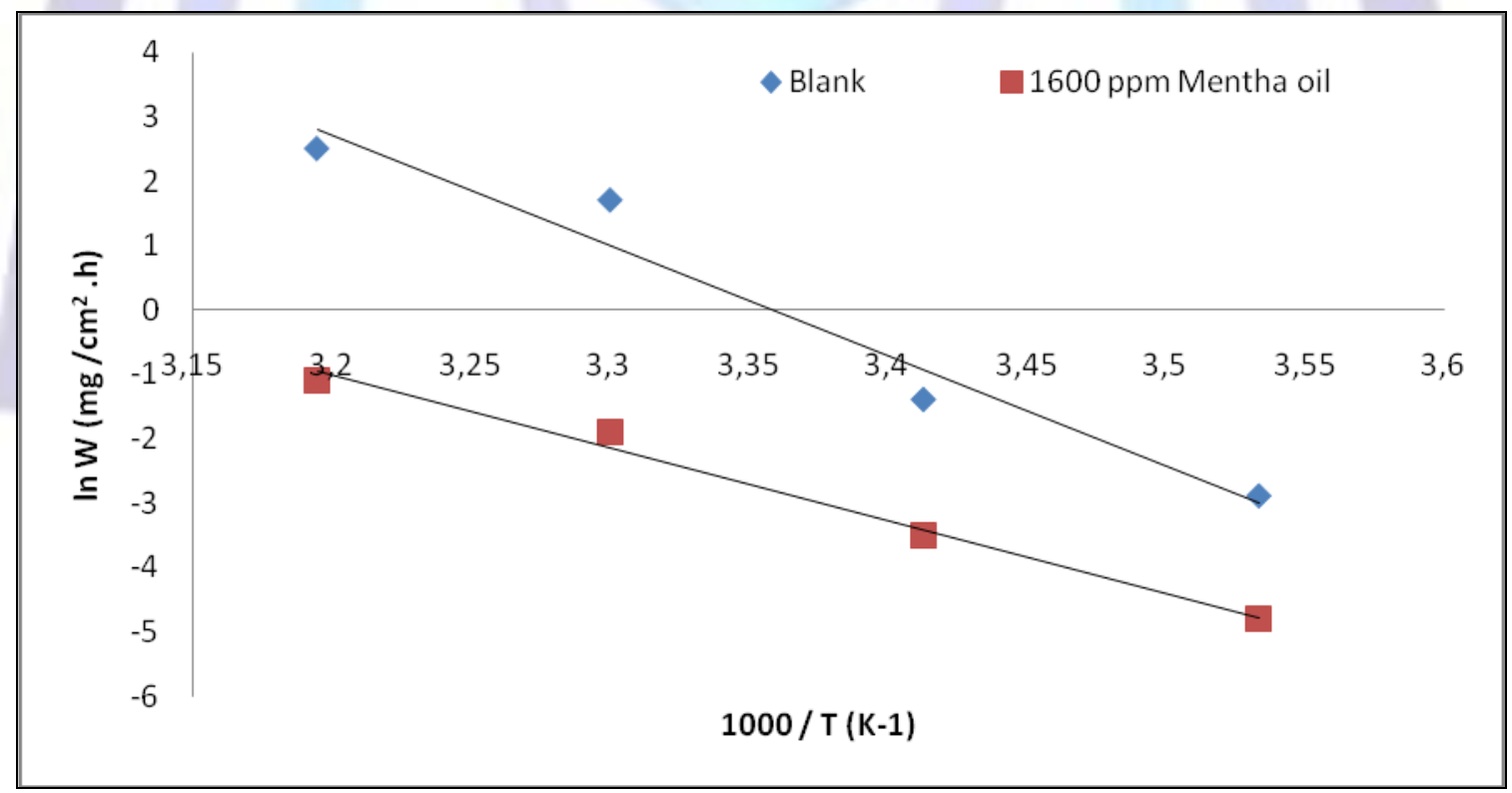

Figure 5. Arrhenius plots of aluminum in uninhibited and inhibited.

Arrhenius plots for the corrosion rates of aluminum are shown in Fig. 5. The calculated values of activation energies from the slopes are 48.55 and $73.70 \mathrm{~kJ} / \mathrm{mol}$ for blank and with the addition of $1600 \mathrm{ppm}$ of mentha spicata oil, respectively.

It is found that the activation energy is increases in the presence of inhibitor. Furthermore, the decrease of E\% is explained due to the physisorption of inhibitor molecule on the steel surface [25]. The lower value of $E_{a}$ of the corrosion process in an inhibitors presence when compared to that in its absence is attributed to its chemisorption [26]. 


\section{3-7 Adsorption isotherm}

The dependence of the fraction of the surface covered $\ominus$ obtained by the ratio $E \% / 100$ as a function of the oil concentration (C) was graphically fitted for Langmuir, Temkin and Frumkin adsorption isotherms. Fig. 6 shows the dependence of $\mathrm{C} / \Theta$ as a function of the oil concentration. The curve obtained clearly shows that the data fit well with Langmuir adsorption isotherm and this was found to be the best description of the adsorption behaviour of the studied inhibitor, which obeys:

$$
\frac{c}{\ominus}=\frac{1}{K a d s}+C
$$

C is the inhibitor concentration; $\ominus$ is the fraction of the surface covered, Kads is the adsorption coefficient.

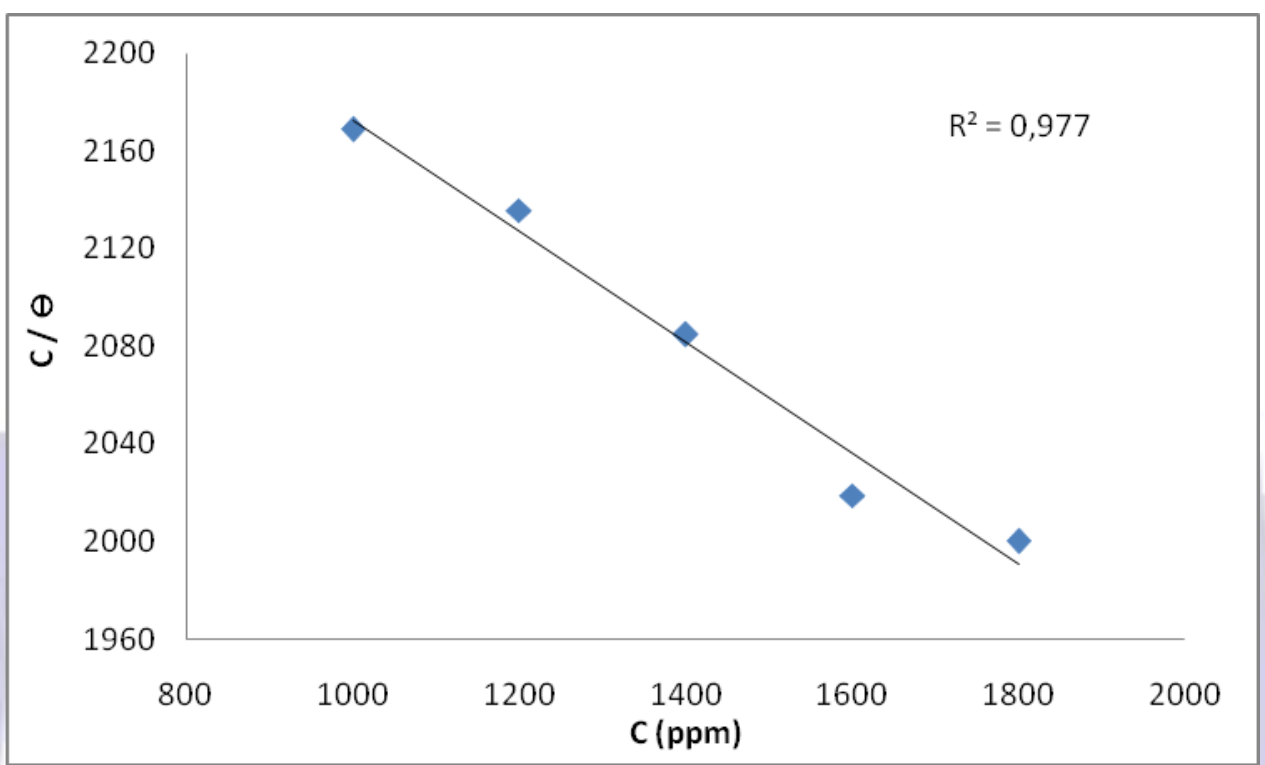

Figure 6. Langmuir adsorption isotherm of mentha oil on the aluminum surface.

The literature shows that the adsorption of heterocyclic compounds occurs with the aromatic rings mostly perpendicular with respect of the metal surface at low concentration, but at elevated inhibitor concentration the molecules are reoriented to the parallel mod [26]. Besides, the adsorption phenomenon may be made by carvone as the principal constituent of the essential oil of mentha spicata. But as the natural oil contains so many components, the inhibitory action may also be due to synergistic intermolecular of the active molecules of this oil [27].

\section{4- Conclusions}

From the overall experimental results the following conclusions can be deduced:

- chemical analysis showed carvone as the major component of mentha spicata essential oil;

- mentha spicata oil acts as good inhibitor for the corrosion of aluminum in $0.1 \mathrm{Na}_{2} \mathrm{CO}_{3}$ medium;

- the inhibition efficiency of mentha spicata oil increases with concentration to attain $82 \%$ at $1600 \mathrm{ppm}$;

- the inhibition efficiency of mentha spicata oil decreases with the rise of temperature;

- the mentha essential oil acts on aluminum surface as mixed inhibitor with a physisorption mechanism.

\section{References}

[1] S. Zaromb. J. Electrochem. Soc. 109 (1962) 1125.

[2] B. Bouyanzer, B. Hammouti, L. Majidi, Matt. Lett. 60 (2006) 2840.

[3] S. Cheng, S. Chen, T. Liu, X. Chang, Y. Yin, Matt. Lett. 61 (2007) 3276.

[4] O. Avwiri, F.O. Igho, Matt. Lett. 57 (2003) 3705.

[5] K.O. Orubite, N.C. Oforka, Matt. Lett. 58 (2004) 1768. 
[6] A.M. Abdel-Gaber , B.A. Abd-El-Nabey, I.M. Sidahmed, A.M. El-Zayady, M. Saadawy, Corrosion Science 48 (2006) 2765-2779

[7] A.M. Abdel-Gaber, E. Khamis, H. Abo-EIDahab, Sh. Adeel Mater. Chem. and Phys. 109 (2008) 297-305

[8] A.A. El Hosary, R.M. Saleh, A.M. Shams El Din, Corros. Sci. 12 (1972) 897.

[9] G.O. Avwiri, F.O. Igho, Mater. Lett. 57 (2003) 3705.

[10] A.M. Abdel-Gaber* , E. Khamis, H. Abo-Eldahab, Sh. Adeel. Mater. Chem. and Phys.124 (2010) 773-779

[11] A.Y. El-Etre, Corros. Sci. 40 (1998) 1845.

[12] A.Y. El-Etre, M. Abdallah, Corros. Sci. 42 (2000) 738.

[13] A.Y. El-Etre, Corros. Sci. 43 (2001) 1031.

[14] A.Y. El-Etre, Corros. Sci. 45 (2003) 2485.

[15] A.Y. El-Etre, M. Abdallah, Z.E. El-Tantawy, Corros. Sci. 47 (2005) 385.

[16] V.P. Barannik, I.N. Putilova, Uch. Zap. Mosk. gosud. Univ., No. 78, 1945.

[17] D. Schweinsgberg, G. George, A. Nanayakkawa, D. Steinert, Corros. Sci. 28(1988) 33.

[18] F. Bensabah, S. Houbairi, M. Essahli, A. Lamiri, J. Naja, Port. Electrochim. Acta. 31 (2013) 195-206

[19] Znini M, Bouklah M, Majidil L, S. et al. Int J Electrochem Sci. 2011;6:691.

[20] El Hassani FZ, Zinedine A, Amraoui MB, et al. Hazardous Materials G Model HAZMAT-9996; No. P7.

[21] Bensabah F, A. Lamiri A, Naja J. Eng Sci Tech Int J (ESTIJ). 2013;3.N1.

[22] Tsuru T, Haruyama S, Gijutsu B. J Jpn Soc Corros Eng. 1978;27:573.

[23] Y. Dehri, M. Erbil, Corros.Sci., 42 (2000) 969.

[24] K.Aramaki, M. Hagiwara, and H. Nishihara, Corros. Sci., 5 (1987) 487.

[25] Dahmani M, Et-Touhami A, Al-Deyab SS, et al. Int J Electrochem Sci. 2010;5:1060.

[26] Zarrouk A, Warad I, Hammouti B, et al. Int J Electrochem Sci. 2010;5:1516.

[27] J.O.M. Bockris, B. Young, J. Electrochem. Soc. 138 (1999) 2237. 